\title{
Utilisation de l'électrophorèse sur gel de polyacrylamide pour caractériser la dégradation in sacco et enzymatique des fractions protéiques du tourteau de soja
}

\author{
J Aufrère, D Graviou, P Cerneau \\ INRA, centre de Clermont-Ferrand Theix, station de recherches sur la nutrition \\ des herbivores, unité de la valeur alimentaire, 63122 Saint-Genès-Champanelle, France
}

\begin{abstract}
Summary - Use of polyacrylamide gel electrophoresis for characterization of in sacco and enzymatic degradation of soyabean meal protein components. Analysis of in sacco and enzymatic residues of soyabean meal by sodium dodecylsulphate-polyacrylamide gel electrophoresis (SDS-PAGE) shows that protein components vary considerably in their rate of breakdown. Among the solubilised forms of nitrogen after enzymatic degradation, proteins and short peptides are in important concentration.
\end{abstract}

La dégradabilité théorique $(D T)$ de l'azote dans le rumen est nécessaire au calcul de la valeur PDI des aliments. Elle est mesurée par la technique des sachets de nylon ou peut être estimée par une technique enzymatique (Aufrère et Cartailler, 1988); elle varie suivant la composition des fractions protéiques de l'aliment. Le travail présenté a pour but de comparer, sur les résidus des cinétiques de dégradation in sacco et enzymatique, les différentes fractions protéiques du tourteau de soja (globulines 7S et 11S) par électrophorèse sur gel de polyacrylamide, et de caractériser les différentes formes d'azote soluble après hydrolyse enzymatique.

Matériel et méthodes - Les résidus des cinétiques de dégradation in sacco (Vérité et al, 1987) et enzymatique d'un tourteau de soja du commerce $(D T=.68,5)$ ont été utilisés. Les fractions protéiques des globulines $7 \mathrm{~S}$ et $11 \mathrm{~S}$ du tourteau de soja ont été séparées par la technique de Thanh et Shibasaki (1976). L'électrophorèse a été réalisée sur gel de polyacrylamide en présence de sodiumdodécylsulfate (SDS-PAGE) selon la technique de Laemmli (1970) en utilisant un gel à $12,5 \%$ en acrylamide.
Sur les surnageants, après hydrolyse enzymatique, on a dosé l'azote total (méthode Kjeldahl), les protéines (par différence après précipitation avec de l'acide trichloracétique), l'azote ammoniacal (méthode de Conway), l'azote $\alpha$-aminé (méthode au TNBS).

\section{Résultats et discussion}

Comparaison des électrophorèses Les globulines, fraction protéique importante des graines de légumineuses, sont constituées de 2 fractions de type $7 \mathrm{~S}$ (conglycinines) et $11 \mathrm{~S}$ (glycinines). On observe (fig 1) que dans les 2 types de résidus, les conglycinines sont rapidement dégradées (les $\alpha$ et $\alpha^{\prime}$ le sont complètement à $2 \mathrm{~h}$, les $\beta$ disparaissent progressivement jusqu'au temps $24 \mathrm{~h}$ ), alors que les glycinines le sont beaucoup moins (les sous-unités basiques ne seraient pas dégradées, et les sous-unités acides ne le seraient que lentement). Les fractions protéiques dégradées sont donc les mêmes in sacco et après hydrolyse enzymatique, mais elles le sont plus rapidement in sacco (ce qui confirme aussi les proportions d'azote disparu à $24 \mathrm{~h}$ in sacco (93\%) ou solubilisé par les enzymes $(74,7 \%))$. 


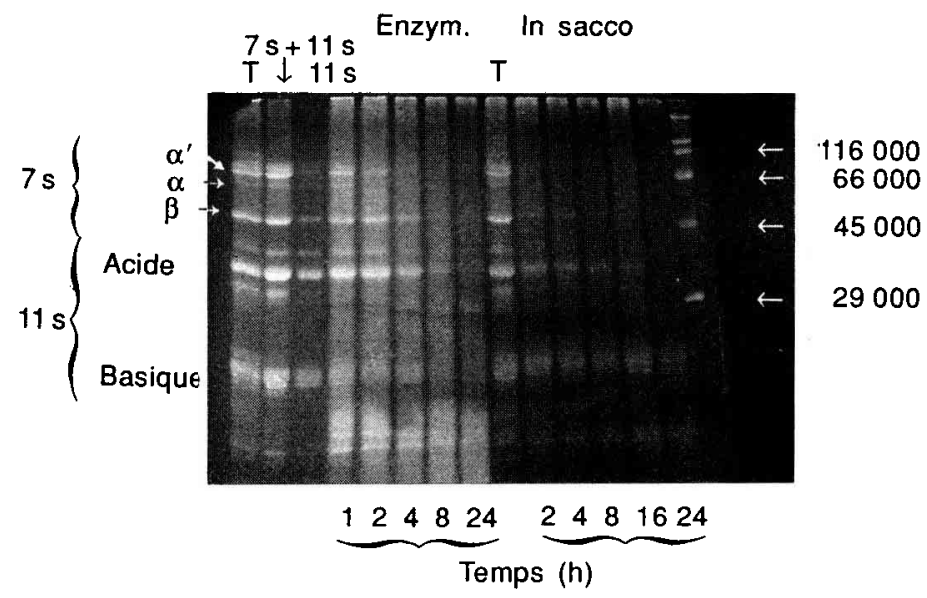

Fig 1. Diagramme électrophorétique du tourteau de soja témoin $(T)$, des globulines extraites du témoin $(7 S+11 S$ et $11 S)$, des résidus après hydrolyse enzymatique et in sacco.

Différentes formes d'azote solubilisé après hydrolyse enzymatique - Une faible fraction de l'azote du surnageant est sous forme d'acides aminés tandis qu'une fraction importante est sous forme de protéines et de petits peptides (tableau I) qui proviendraient de l'hydrolyse des fractions 75 et $11 S$ (sousunités acides). II serait intéressant de savoir s'il en est de même dans le rumen, car une certaine proportion de l'azote solubilisé - mais restant sous forme de protéines et de peptides pourrait échapper à la dégradation dans le rumen.

Aufrère J, Cartailler D (1988) Ann Zootech $37,255-270$

Laemmli UK (1970) Nature (Lond) 277, 680685

Thanh VH, Shibasaki K (1976) J Agric Food Chem 24, 1117-1121

Vérité R, Michalet-Doreau $B$, Chapoutot $P$, Peyraud JL, Poncet C (1987) Bull Tech CRZV INRA Theix, 70, 19-34

Tableau I. Différentes formes d'azote solubilisé (en $\% \mathrm{~N}$ total de l'aliment) dans le surnageant après hydrolyse enzymatique.

\begin{tabular}{lrrrrr}
\hline & \multicolumn{5}{c}{ Temps en $h$} \\
& \multicolumn{1}{c}{ 1 } & \multicolumn{1}{c}{2} & 4 & \multicolumn{1}{c}{8} & \multicolumn{1}{c}{24} \\
\hline $\mathrm{N}$ total dégradé & 26,7 & 36,2 & 49,4 & 59,7 & 74,7 \\
$\mathrm{~N}$ sous forme de protéines & 15,7 & 22,4 & 30,3 & 37,5 & 40,6 \\
$\mathrm{~N} \alpha$-aminé & 1,4 & 1,9 & 2,9 & 4,1 & 7,0 \\
$\mathrm{~N}$ sous forme $\mathrm{NH}_{3}$ & 0,6 & 0,7 & 0,8 & 0,7 & 1,2 \\
$\mathrm{~N}$ sous forme de petits peptides & 9,0 & 11,2 & 15,4 & 17,4 & 25,9 \\
(obtenue par différence) & & & & & \\
\hline
\end{tabular}

